Círculo de Lingüística Aplicada a la Comunicación ISSN: $1576-4737$

\title{
Alicante 2018: XLVII Simposio de la Sociedad Española de Lingüística
}

http://sel.edu.es/presentacion-simposio-2018

\section{Presentación}

El próximo Simposio se celebrará en la Universidad de Alicante, del 23 al 26 de enero de 2018, y tendrá las siguientes características:

- Se celebrarán cuatro sesiones monográficas de comunicaciones.

- El número de comunicaciones que no se encuadren en las sesiones monográficas será, por razones organizativas, limitado.

- Se presentarán tres ponencias plenarias.

Las actividades previstas son las que se indican a continuación:

Comunicaciones de tema libre, con preferencia para las que se encuadren en las sesiones, con una duración de 30 minutos — 20 de exposición y 10 de debate-.

\section{Ponencias}

- Dra. Dolores Azorín Fernández (Universidad de Alicante): “El tratamiento del léxico con variación diafásica en la trayectoria del DRAE/DLE”.

- Dr. Bruno Camus Bergareche (Universidad de Castilla - La Mancha):

"Variación sintáctica en español en situaciones de contacto"

- Dr. José María Lahoz Bengoechea (Universidad Complutense) [Premio SEL para tesis doctoral 2015-2016]: "El refuerzo consonántico como marca de la estructura prosódica: sus efectos en español”

\section{Sesiones monográficas de comunicaciones}

- Interacción verbal, oralidad y multimodalidad, coordinada por los Dres. Raquel Hidalgo Downing (Universidad Complutense) y Antonio Hidalgo Navarro (Universidad de Valencia).

- La gramática en la enseñanza no universitaria, coordinada por los Dres. Ángel Gallego Bartolomé (Universitat Autònoma de Barcelona), Edita Gutiérrez Rodríguez (Universidad de Castilla - La Mancha) y Ángeles Carrasco Gutiérrez (Universidad de Castilla - La Mancha). 
- Categorías semiléxicas: haciendo balance entre el contenido léxico y la función gramatical, coordinada por las Dras. Begoña Sanromán Vilas (Universidad de Helsinki) y Ángeles Carrasco Gutiérrez (Universidad de Castilla - La Mancha).

- Los diccionarios del español: pasado, presente y futuro, coordinada por los Dres. José Joaquín Martínez Egido (Universidad de Alicante) e Isabel Santamaría Pérez (Universidad de Alicante).

Las fechas importantes para los participantes son las siguientes:

- Apertura del plazo de envío de resúmenes: 15 de septiembre.

- Cierre del plazo de envío de resúmenes: 30 de octubre.

- Aceptación de propuestas: a lo largo del mes de noviembre. 